\title{
CRiterios ADOPTADOS PARA LA CONSERVACIÓN de los restos de estructura naval del Pecio Zencity de Puerto Madero (Buenos Aires, Argentina): ¿iRE-ENTERRAR PARA CONSERVAR?!
}

\author{
Eva Tavella *
}

\begin{abstract}
Resumen
El presente artículo pretende dar a conocer, mediante un lenguaje accesible a la comunidad, en qué consisten las prácticas de re-enterramiento implementadas en el proyecto del denominado Pecio de Zencity. Así mismo, se exponen los criterios y fundamentos que llevan a la elección de este tipo de intervención como método de conservación para el patrimonio arqueológico en general, aludiendo a ejemplos de casos similares en otras partes del mundo.
\end{abstract}

Palabras clave: Re-enterramiento, restauradores, medioambiente, homeostasis, consolidación.

\begin{abstract}
This article aims to make known, through a language accessible to the community, what are the reburial practices implemented in the so-called Zencity Wreck project. Likewise, the criteria and the foundations that lead to the choice of this type of intervention as a method of conservation for the archaeological heritage in general are presented, alluding to examples of similar cases in other parts of the world.
\end{abstract}

Keywords: Re-burial, restorers, environment, homeostasis, consolidation.

\section{Introducción \\ ¿¿Re-enterrar para conservar?!}

Síííí!! Y sí, sí: la respuesta es “sí”; aunque a priori pueda resultar contradictorio, sobre todo para aquellas personas que no están muy familiarizadas con la conservación del patrimonio arqueológico.

Por ello nos parece oportuno explicar cómo y por qué re-enterrar ciertos hallazgos arqueológicos es válido, poniendo en contexto el caso y fundamentando con normativas vigentes y casos precedentes/precursores.

\section{Contextualización}

Estamos hablando en general de patrimonio arqueológico que, para su rescate y estudio, fue excavado y desenterrado del medioambiente suelo" (más o menos saturado de humedad -agua-).

\footnotetext{
* Restauradora de Bienes Arqueológicos. Dirección General de Patrimonio Museos y Casco Histórico del Ministerio de Cultura de la Ciudad Autónoma de Buenos Aires (DGPMYCH - GCABA). tavellarestauracion@gmail.com
} 
Es el caso de los restos de la estructura de madera de un buque que se hallaron en diciembre de 2008 en el sitio arqueológico que se denominó "pecio de Zencity" de Puerto Madero, en la ciudad de Buenos Aires. Estos se descubrieron durante la construcción de un complejo de edificios, en un lote de propiedad privada.

Los mismos permanecieron enterrados, con elevados índices de humedad, escasos o nulos niveles de oxígeno, y baja temperatura. Y la constancia o invariabilidad de estos tres parámetros (humedad, oxígeno y temperatura) es lo que propició la conservación de estos restos de madera por casi 300 años.

Entonces, a la hora de rescatar el pecio se plantean las diferentes posibilidades para su conservación presente y futura: lo ideal sería exhibirlo al público, que todo el mundo pueda verlo. Pero para poder exhibirlo primero hay que consolidarlo. ¿Por qué? Porque, como dijimos, los restos del barco estuvieron cubiertos de tierra húmeda durante un prolongado periodo. $Y$ en ese tiempo, alcanzaron un equilibrio con ese medio que los rodeaba: es decir presentaban los mismos valores de humedad, oxigenación y temperatura que el terreno. Al extraerlos de ese ambiente terroso por medio de la excavación arqueológica, los restos pasan al medioambiente aéreo, en el que deberán permanecer para poder ser apreciados en una exhibición.

El aire es mucho más seco que el suelo, tiene muchísimo más oxígeno, y su temperatura sufre oscilaciones muy por encima y muy por debajo de las existentes en el suelo. ¿Y qué va a suceder con el barco (sus restos en realidad) ante estas nuevas condiciones ambientales? Se va romper el equilibrio que había alcanzado con el sedimento que lo cubrió y va a "intentar adaptarse" a las nuevas condiciones del aire.

Durante ese proceso de adaptación, el agua que impregnaba la madera se evaporará, debilitando la estructura interna de ésta, que puede llegar a desintegrarse por completo.

Estos deterioros pueden evitarse o al menos minimizarse mediante tratamientos de consolidación: lo que a grandes rasgos supone sustituir ese agua por una sustancia que le otorgue estabilidad estructural a la madera.

Ahora bien: una cosa es consolidar (por ejemplo) un tapón de corcho, y otra muy distinta consolidar un barco (aún cuando lo que tenemos de él sea sólo una tercera o cuarta parte del total del navío).

Y es que los consolidantes son muy caros, y se necesitan litros y litros durante décadas de lenta impregnación para lograr el grado de consolidación deseado, sin quedar claro incluso si dará resultado. ¡Y un equipo numeroso de profesionales restauradores, consolidando, monitoreando el sistema de consolidación, siguiendo el estado de conservación de los materiales, atendiendo los imprevistos, etc, etc!

Esto supone una inversión monetaria, sostenida en el tiempo, que el estado no puede garantizar; menos aún considerando que existe un elevado porcentaje de población cuyas necesidades básicas no están cubiertas. Es decir, hay prioridades sociales que están por encima de la conservación del patrimonio, y que no se pueden obviar.

Por otro lado, la conservación del patrimonio arqueológico, tal como se la concibe hoy, es una disciplina joven y esto incide negativamente, en dos aspectos:

- Existen en el mundo pocas experiencias de consolidación de grandes estructuras navales como para garantizar que dichos tratamientos sean realmente efectivos.

- Es frecuente que, quienes toman decisiones económicas y de gestión, a la hora de realizar tratamientos de conservación, desconozcan o subestimen la existencia de profesionales restauradores correctamente formados, y de la importancia y alcance de sus intervenciones. Esto se traduce, muchas veces, en la escasa y/o inadecuada adjudicación de recursos humanos, materiales y presupuestarios.

Ante este panorama: cifras astronómicas de dinero y de consolidante, décadas de tratamientos de conservación, e inseguridad en cuanto a la efectividad de los métodos disponibles; se toma, en el 
caso de los restos rescatados del pecio de Puerto Madero, la determinación de devolver los restos del barco a un medioambiente suelo, de características muy similares a las del sitio arqueológico de origen, que garanticen una conservación natural del barco (Figura 1). Para ello se lo traslada y re-entierra en un predio delimitado, propiedad del gobierno de la Ciudad Autónoma de Buenos Aires, lo cual asegura que el terreno no será intervenido con fines inmobiliarios.

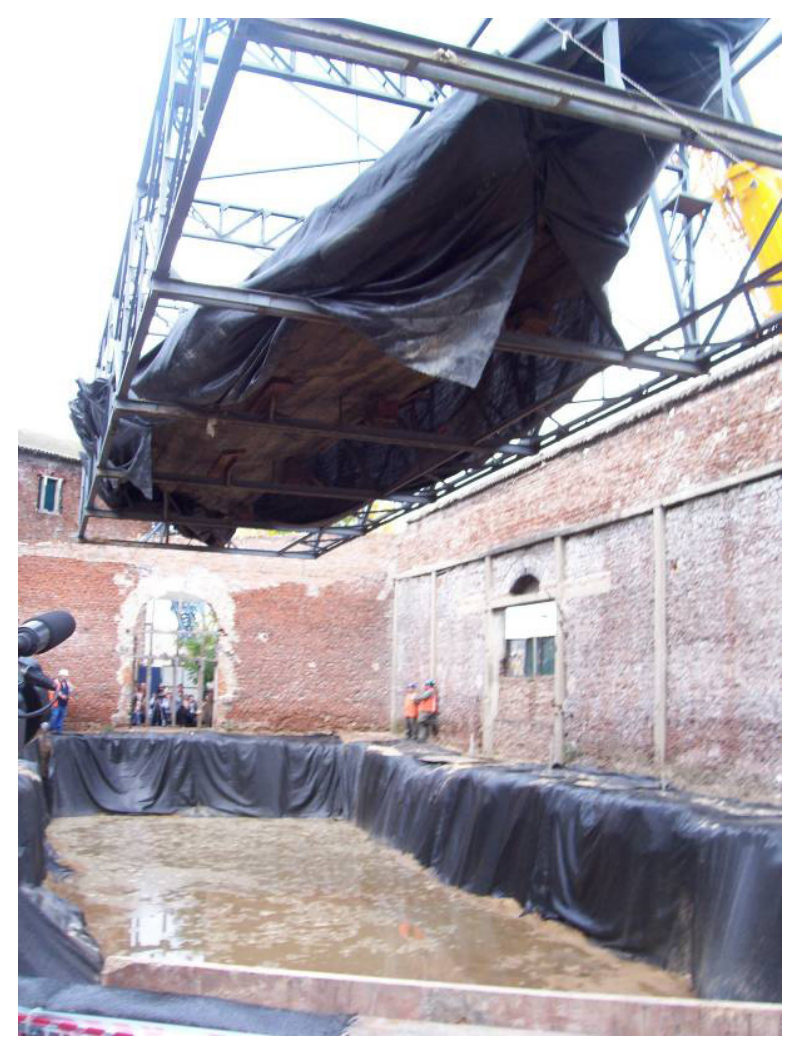

Figura 1. Proceso de re-enterramiento de la estructura naval del Pecio Zencity (ph. E. Tavella)

Lo ideal hubiera sido dejar la estructura en su lugar de hallazgo original, en el contexto que la albergó durante casi 300 años, pero como se dijo al principio, en el sitio se construyeron cinco torres de edificios, por lo que dejar el barco allí era equivalente a perderlo definitivamente.

Mediante el re-enterramiento se lo preserva para que pueda ser extraído cuando se disponga de tratamientos cuya efectividad esté garantizada, y se cuente con medios económicos suficientes.

\section{Otros casos donde se reflejan algunas estas problemáticas y/o los criterios adoptados}

\section{El Vasa}

Este barco es un caso emblemático: más de 50 años de tratamientos de conservación permanentes. Se trata de un buque de guerra sueco que naufragó momentos después de su botadura, en 1628. Recién en 1961, después de años de estudios y preparación, fue extraído a la superficie. Entonces se planteó el problema de su conservación dice textualmente la página web del museo que lo alberga -hoy en día este problema sería planteado antes de plantear la excavación- y continúa: "No se pueden dejar sin tratar restos de madera que han permanecido sumergidos en agua durante tanto tiempo. A la larga, la madera se cuartearía y acabaría fragmentándose." (Vasa Museet https://www.vasamuseet.se/es , consultada 15 noviembre 2016). 
En la actualidad, se siguen haciendo investigaciones para su conservación, y se mantiene su entorno bajo una atmósfera estable.

\section{El Mary Rose}

Navío de guerra inglés, otro caso emblemático de la arqueología subacuática y la problemática en su conservación. Con casi 500 años de historia, se fueron recuperando objetos del pecio desde la década de 1970, y recién fue extraído de los fondos marinos en 1982 (The Mary Rose Museum http:// www.maryrose.org/your-visit/, consultada 15 noviembre 2016).

La imagen a continuación habla por sí sola de la costosa infraestructura necesaria para la consolidación y conservación en condiciones estables (Figura 2).

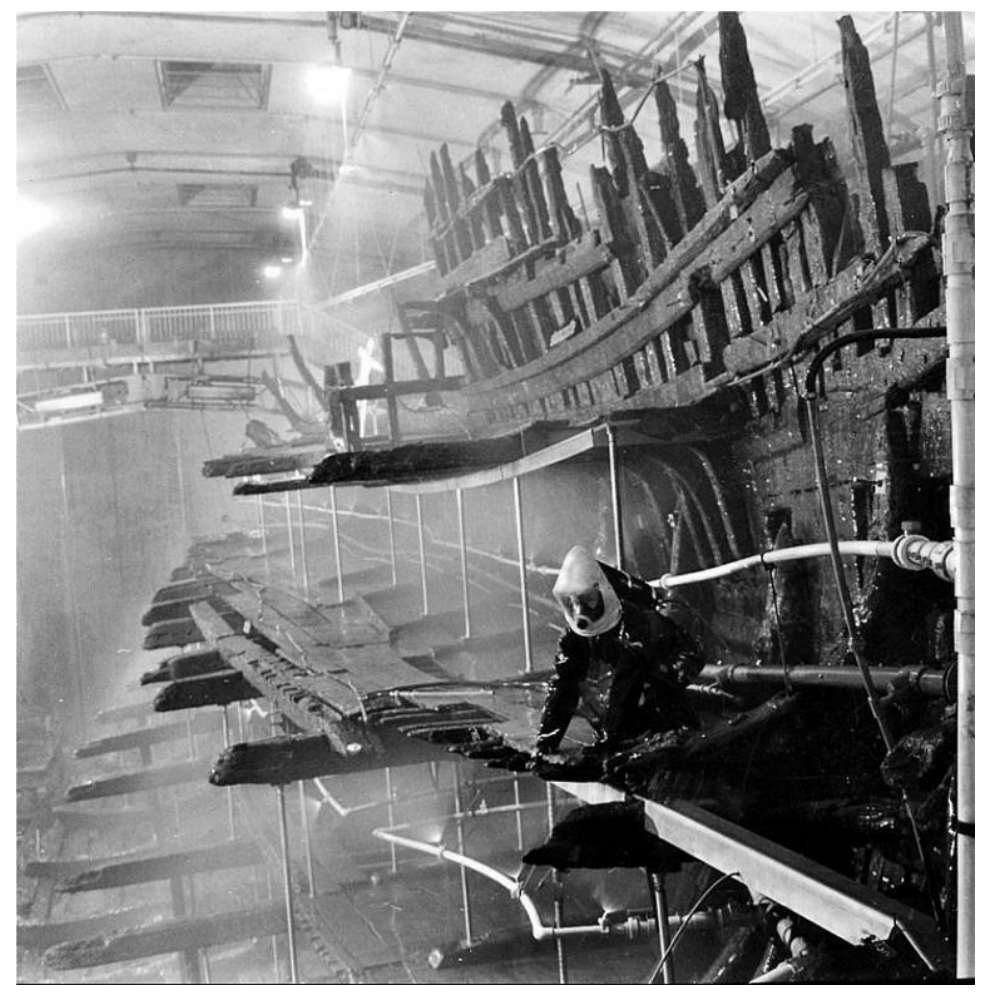

Figura 2. Proceso de consolidación de la estructura naval del Pecio Mary Rose (ph. http://www.maryrose.org)

\section{La conservación in situ del patrimonio sumergido}

Ante los resultados y dificultades arrojados por experiencias anteriores, muchos organismos e instituciones del mundo se han volcado en los últimos años hacia la conservación de los yacimientos como tales, es decir: sin excavarlos; conservarlos en sus emplazamientos (in situ).

Tal es la postura de la Subdirección de Arqueología Subacuática del INAH (Instituto Nacional de Antropología e Historia), México; desde donde se argumenta, entendemos acertadamente, que al permanecer in situ se conserva el estado de homeostasis (equilibrio) alcanzado por los materiales con respecto al medio acuático (Zuccolotto, 2013) 


\section{En tierra (in situ o no), volver a tapar}

Existen múltiples ejemplos de yacimientos arqueológicos aflorados a raíz de alguna construcción vial, o complejo urbanístico. Y lo más común en estos casos, respondiendo a los mismos criterios planteados en este artículo, es registrar el sitio y volver a enterrarlo, modificando (o no) el proyecto de obra civil o arquitectónica.

Al respecto, citamos dos casos. Vestigios arqueológicos de la antigua población de Amecameca, en México, fueron descubiertos durante la ampliación de una carretera; y se decidió volver a cubrirlos de tierra (Fernández, 2012). Restos romanos, existentes en el terreno de un complejo de viviendas en Andalucía, se mantuvieron protegidos y enterrados hasta que surja la posibilidad y/o necesidad de estudiarlos correctamente (López Priego, 2016). Esto genera el descontento entre los vecinos hacia las autoridades competentes, reacción muy frecuente ante la incomprensión de criterios.

La bibliografía especializada en conservación y restauración de bienes arqueológicos fundamenta estos criterios, según los cuales:

- los materiales que estuvieron sumergidos o húmedos deben mantener esos niveles de humedad mediante el sedimento que los rodea;

- deben favorecerse o reproducirse las condiciones climáticas que resultaron propicias para la conservación mientras los bienes estuvieron enterrados/sumergidos (García Fortes, y Flos Travieso, 2008);

- volver a enterrar, o rellenar con la misma tierra, los materiales hallados constituye una intervención de conservación que garantiza la estabilidad de las piezas (Boletín ICCROM 30, 2004:12 )

En cuanto a los documentos internacionales (Cartas, Convenciones, Recomendaciones, etc.) para la conservación del patrimonio arqueológico en general y subacuático; todos hacen referencia a la necesidad y responsabilidad de preservar dicho patrimonio para las generaciones presentes y/o futuras, con los medios y recursos disponibles más apropiados, priorizando la conservación in situ. Citamos algunos puntos donde se hace referencia al tema:

- Convención sobre la Protección del Patrimonio Cultural Subacuático - Organización de las Naciones Unidas para la Educación, la Ciencia y la Cultura (UNESCO) París, 2 de noviembre de 2001. Artículo 2 - Objetivos y principios generales 4, 5, 6. :

4. Los Estados Partes, individual o conjuntamente, según proceda, adoptarán todas las medidas adecuadas conformes con esta Convención y con el derecho internacional que sean necesarias para proteger el patrimonio cultural subacuático, utilizando a esos efectos, en función de sus capacidades, los medios más idóneos de que dispongan. 5. La preservación in situ del patrimonio cultural subacuático deberá considerarse la opción prioritaria antes de autorizar o emprender actividades dirigidas a ese patrimonio. 6. El patrimonio cultural subacuático recuperado se depositará, guardará y gestionará de tal forma que se asegure su preservación a largo plazo.

- Carta Internacional para la Gestión del Patrimonio Arqueológico (1990) Preparada por el Comité Internacional para la Gestión del Patrimonio Arqueológico (ICAHM) y adoptada par la Asamblea General del ICOMOS en Lausana en 1990. Legislación y Economía Artículo 3:

La protección del patrimonio arqueológico debe constituir una obligación moral para cada ser humano. Pero también es una responsabilidad pública colectiva. Esta responsabilidad debe hacerse efectiva a través de la adopción de una legislación adecuada y mediante la provisión de fondos suficientes para financiar programas que garanticen una gestión eficaz del patrimonio arqueológico. El patrimonio arqueológico es un bien común para toda sociedad humana; por tanto, constituye un deber para todos los países asegurar la disponibilidad de los fondos adecuados para su protección. La legislación debe garantizar la conservación del patrimonio arqueológico en función de las necesidades, la historia y las tradiciones de cada país y región, y esmerarse para favorecer la conservación 
"in situ" y los imperativos de la investigación. La legislación debe basarse en la idea de que el patrimonio arqueológico es la herencia de la humanidad entera y de grupos humanos, no la de personas individuales o de determinadas naciones. La legislación debe prohibir toda destrucción, degradación o alteración por modificación de cualquier monumento o conjunto arqueológico, o de su entorno sin el permiso de la autoridad arqueológica competente. La legislación debe exigir, por principio, una investigación previa a la redacción de una documentación arqueológica completa en cada uno de los casos en que haya sido autorizada una destrucción del patrimonio arqueológico. La legislación debe exigir un mantenimiento correcto y una conservación satisfactoria del patrimonio arqueológico y proveer los medios para ello. La legislación debe prever las sanciones adecuadas y correspondientes a las infracciones de las normas relativas al patrimonio arqueológico. En el caso de que la legislación extendiese su protección sólo al patrimonio declarado oficialmente de interés, habría que tomar medidas dirigidas a la protección provisional de monumentos y conjuntos no protegidos o recientemente descubiertos, hasta que se proceda a una valoración arqueológica. Uno de los mayores riesgos físicos para el patrimonio arqueológico se deriva de los programas de desarrollo y rehabilitación. La obligación para los autores de dichos programas de asegurar que se proceda a un estudio de impacto arqueológico antes de definir sus coordenadas de actuación, debe constar en una legislación adecuada que estipule que el coste de dicho estudio debe estar incluído en el presupuesto del proyecto. El principio según el cual cualquier programa de desarrollo y rehabilitación ha de estar concebido de manera que se reduzcan al mínimo.!

- Carta Internacional sobre la Conservación y la Restauración de Monumentos y Sitios (Carta de Venecia 1964) II Congreso Internacional de Arquitectos y Técnicos de Monumentos Históricos, Venecia 1964. Adoptada por ICOMOS en 1965. EXCAVACIONES Artículo 15. (Consejo Internacional de Monumentos y Sitios - ICOMOS) :

El arreglo de las ruinas y las medidas necesarias para la conservación y protección permanente de los elementos arquitectónicos y de los objetos descubiertos deberán ser asegurados. Además, todas las iniciativas deberán tomarse con el fin de facilitar la comprensión del monumento puesto al día, sin desnaturalizar nunca su significado. Todo trabajo de reconstrucción deberá excluirse a priori; tan solo la "anastilosis" o recomposición de las partes existentes pero desmembradas, puede tenerse en cuenta, Los elementos de integración se reconocerán siempre y representarán el mínimo necesario para asegurar las condiciones de conservación de un monumento y restablecer la continuidad de sus formas.

\section{Consideraciones finales}

Al momento de tomar decisiones pensamos que era importante tener en cuenta el contexto de gestión del sitio, para plantear a largo plazo una estrategia de ejecución, mantenimiento y seguimiento adecuados para su protección. La resolución tomada en el año 2009 entre los científicos y el gobierno de la ciudad (a cargo del bien patrimonial) fue la de considerar una alternativa viable sin generar un costo elevado y constante y sin tener la seguridad de que el presupuesto para otro tipo de conservación se mantuviera a través del tiempo.

En el caso de los restos del pecio de Zencity, la estructura de la embarcación ha sido reenterrada bajo los estándares de control que se exigen internacionalmente, ya que cuando no hay opciones técnicas para mantener expuesto el hallazgo, es mejor regresarlo a las condiciones en las que se conservó por tanto tiempo. Tal vez en el futuro las cosas cambien...

\section{Referencias}

BOLETIN ICCROM 20. (2004). Centro Internacional de estudios para la Conservación y Restaura- 
ción de Bienes Culturales. Boletín electrónico. https://www.iccrom.org/sites/default/files/2017-02/ iccrom_newsl30-2004_es.pdf. (consultado 17 febrero 2017).

FERNÁNDEZ, E. (2012). Nota de prensa en El Universal: Amecameca México; 10 de mayo. http:// www.eluniversaledomex.mx/otros/nota29470.html (consultado 24 noviembre 2016)

GARCÍA FORTES, S. y FLOS TRAVIESO, N. (2008). Conservación y restauración de bienes arqueológicos. Madrid: Editorial Síntesis.

LÓPEZ PRIEGO, N. (2016). Nota de prensa en Diario Jaén: Un vecino acusa a la Junta de que "prefiere enterrar vestigios a integrarlos". Jaén, España -27/02/2016, http://www.diariojaen.es/ (consultado 24 noviembre 2016).

VV AA. (1965). Carta internacional sobre la conservación y la restauración de monumentos y sitios (carta de Venecia 1964) ICOMOS / UNESCO / ONU http://www.icomos.org/charters/venice_sp.pdfhttp://portal.unesco.org/es/ev.php-URL_ID=13062\&URL_DO=DO_TOPIC\&URL $\underline{\text { SECTION }=201 . h t m l}$ (consultado 03 noviembre 2016).

VV AA. (1991). Carta internacional para la gestión del patrimonio arqueológico, Lausana, ICOMOS. http://www.icomos.org/charters/arch_sp.pdf (consultado 03 noviembre 2016) .

VVAA. (2001). Convención sobre la protección del patrimonio cultural subacuático, París: UNESCO / ONU. http://portal.unesco.org/es/ev.php-URL_ID=13520\&URL_DO=DO_TOPIC\&URL SECTION=201.html (consultado 03 noviembre 2016).

VV AA. (2004). News $n^{0} 30$, ICCROM (Centro Internacional de Estudios para la Conservación y Restauración de los Bienes Culturales) UNESCO / ONU. http://www.iccrom,org/ifrcdn/pdf/ICCROM news130-2004 es.pdf (consultado 24 noviembre 2016).

VV AA. The Mary Rose Museum, Mouthport, http://www.maryrose.org/your-visit/ (web consultada 15 noviembre 2016).

VV AA. Vassa Museet, Estocolmo https://www.vasamuseet.se/es (web consultada 15 noviembre 2016).

ZUCCOLOTTO, A. (2013). La conservación in situ del patrimonio sumergido y sus amenazas. Reserva de la biosfera banco Chinchorro. Guadalajara, Jalisco - México, Escuela de Conservación y Restauración de Occidente, http://www.ecro.edu.mx/pdf/memorias_x_foro22-Zuccoloto.pdf (consultado 15 noviembre 2016).

Recibido: $14 / 07 / 2017$

Aceptado: 04/08/2017 